DOI: 10.12957/demetra.2015.15576

\title{
Fontes para história da alimentação e patrimônio alimentar: a coluna "Vamos preparar os quitutes", no Jornal das Moças, nos anos 1950
}

\section{Sources for the history of food and food heritage: the column "Let us prepare delicacies", in the Jarnal dassMbas 1950's}

Maria Cecilia Barreto Amorim Pilla

I Pontifícia Universidade Católica do Paraná, Escola de Educação e Humanidades, Curso de Licenciatura em História. Curitiba-PR, Brasil

Correspondência / Correspondence

E-mail:maria.pilla@pucpr.br

\section{Resumo}

Desde o final da Primeira Guerra Mundial, ganhou força no Brasil a ideia de que a mulher deveria dedicar-se exclusivamente às tarefas domésticas, incluindo aí os papéis de dona de casa e mãe. Essa mulher deveria dedicar-se integralmente aos cuidados da casa e dos filhos. Embora não tenha sido adotado por toda a população, o ideal de família estimulado pelas classes dominantes passou a ser parâmetro. Ora, as matérias relativas ao ambiente privado suscitam ponderações a respeito de temas como gênero, classes sociais, vestuário, moradia e alimento. Esses aspectos se dão no espaço doméstico, onde, na primeira metade do século $\mathrm{XX}$, a mulher tinha maior responsabilidade e funções. Elegeuse como proposta para este trabalho a apreciação de fontes históricas, as colunas "Vamos preparar os quitutes" contidas na revista feminina Jornal das Moças, na década de 1950, período em que o padrão familiar era o do "doce lar", em que os membros da família se encontravam sob a proteção da casa, espaço em que a mulher deveria reinar soberana como dona de casa e mãe. O objetivo foi demonstrar a potencialidade das fontes no sentido de instigar reflexões sobre a construção histórico-cultural de padrões alimentares bem como entender esses padrões em relação ao papel feminino nesse período.

Palavras-chave: História da Alimentação. Patrimônio Alimentar. Fontes Históricas. 


\section{Abstract}

Since the end of World War I, the idea that women should devote themselves exclusively to household tasks, including the roles of the house owner and mother, became strong. Women should devote themselves fully to the care of home and children. Although it has not been adopted by the entire population, the family ideal encouraged by the ruling classes became the parameter. Matters relating to the private environment raise discussion on issues such as gender, social class, clothing, housing and food. These aspects within the household, where in the first half of the twentieth century, women had greater responsibility and functions. It was elected as a proposal for this work the examination of historical sources, the columns "Let us prepare delicacies", in the women's magazine Jornal das Moças, in the 1950 s, during which the familiar pattern was the "sweet home" where family members were under the protection of the house, space where women should reign sovereign as housewives and mothers. The aim was to demonstrate the potential of sources in order to instigate reflections on the historical and cultural construction of food standards and understand these patterns in relation to women's role in this period.

Key words: Food History. Food Heritage. Historical Sources.

\section{Introdução}

O alimento é fundamental para que o ser humano viva, isso é óbvio, mas mesmo que à primeira vista isso pareça ser um tema que beira o senso comum, indo um pouco, mas muito pouco além da superfície, um universo complexo se descarna. A comida é bem mais do que simples alimentar-se; ela é parte da identidade, é patrimônio, é cultura, é história. Mas o acesso a ela é mercado. Isso é o que Ziegler diz, logo no primeiro parágrafo do prefácio que fez à obra "Direito Humano à Alimentação Adequada”.

Para um banqueiro de Wall Street, ou de Zurique, um saco de arroz é uma mercadoria como qualquer outra. Seu preço (que engloba transporte, seguro, armazenamento e outros) é determinado pelas regras do mercado, mais precisamente pela bolsa de mercadorias de Chicago (Chicago Commodity Stock Exchange), onde são fixados diariamente os preços de quase todos os alimentos que existem sobre a terra. Ao invés, para o faminto, o alimento que lhe assegure uma sobrevivência física e psiquicamente saudável e segura é uma questão de vida ou morte. (Sem grifo no original). 
Vemos, portanto, que a questão alimentar não se reduz ao âmbito econômico, embora as políticas públicas que resultam em aumento da oferta de empregos e salários pretendam, na maioria das vezes, permitir o acesso maior da população aos alimentos de qualidade nutricional. Nesse sentido, o assunto necessita estar relacionado a ações que propiciem efetivamente a equidade social e igualdade nas condições de acesso à comida. Todavia, a fome não pode ser reduzida à sua dimensão econômica ou ao seu impacto biológico, ela é um fenômeno muito mais amplo. A fome e a alimentação incorporam dimensões relacionadas à história, à cultura, a fatores psicológicos e religiosos, englobando tudo o que concerne chamar de "dignidade", tanto no sentido das carências nutricionais como nas carências espirituais, simbólicas e culturais. A questão não deve estar unicamente relacionada a quantidades de alimentos, tais como o cálculo de calorias diárias, mas sobretudo à qualidade do que se come, e tudo o que envolve o próprio ato do comer.

Nesse sentido, o gênero feminino ocupa posição de destaque quando o assunto é comida, pois mesmo com todas as transformações históricas ao longo do século XX, o gerenciamento e preparo da alimentação, a manutenção da casa, o cuidado e a educação dos filhos, em muitos dos lares brasileiros ainda é um papel considerado "naturalmente" feminino.

De forma significativa, quando a mulher entrou mais efetivamente para o mundo do trabalho no espaço público ocidental, houve mudanças em relação aos modelos de família, mas ainda assim grande parte das pessoas encara o homem como o provedor e as mulheres como administradoras da casa, ainda que grande parte delas contribua economicamente para o sustento da família.

Quando o tema recai sobre saúde e nutrição da família, são as mulheres que costumam ser as responsáveis pelo bem-estar dos demais membros do grupo. Os registros culinários brasileiros ao longo do século XIX e XX foram dirigidos e/ou elaborados quase que exclusivamente por mulheres. Nesse período, eles circularam entre os espaços privados do feminino, entre a copa, a cozinha, a despensa e a sala de jantar, criando identidades entre mães, filhas, netas, sobrinhas, criadas, agregadas, afilhadas. A partir dessa premissa é que se pretende desenvolver o presente artigo, pois ao longo da história as mulheres foram vistas como fundamentais nos processos de carências alimentares, tanto no que diz respeito à condição biológica na gestação, como na condição de alimentadoras das crianças e da família em geral.

O presente trabalho faz parte de uma pesquisa maior que envolve o levantamento, organização e fichamento de todo o material sobre alimentação contido na revista Jornal das Moças, de 1914 a 1961, período de sua circulação. Neste estudo, especialmente foi escolhido falar sobre a coluna "Vamos preparar os quitutes" no recorte de tempo que é a década de 1950.* Tem como objetivo apresentar o estágio inicial da pesquisa, bem como demonstrar a potencialidade das fontes no

* Jornal das Moças. 1950-1960. Disponíveis todos os seus mais de 2000 volumes de forma digital através da Hemeroteca da Biblioteca Nacional. 
sentido de instigar reflexões sobre a construção histórico-cultural de padrões alimentares, e entender esses padrões em relação ao papel feminino nesse período.

Tendo em conta o exposto, é importante considerar que a presente pesquisa está em seu início, com a colaboração de alunos em iniciação científica, está na fase de leitura e aprofundamento do referencial teórico sobre o tema e do levantamento das fontes.

\section{Desenvolvimento}

O Brasil da passagem do século XIX para o século XX enfrentou um período de intensas transformações, de cunho político. Desde 1889, havia abolido a monarquia e instituído a república; de cunho social, enfrentava novas balizas e desafios frutos do processo de urbanização que acelerava a necessidade de adaptações e que levaram a cabo práticas sociais desenvolvidas pelos governos federais e estaduais, com o objetivo de promover uma intervenção direta, visando adequar a administração pública às novas exigências de uma sociedade em formação, instruída por concepções racionais de "progresso", "ciência” e "civilização".

Tais concepções, guardadas as especificidades, tentavam acompanhar o pensamento reformista que inspirava as grandes metrópoles ao longo do século XIX. A ideologia do mundo ocidental nesse período estava impregnada de uma crença sincera no progresso - um mito baseado no significado de aperfeiçoamento, principalmente para os elementos das elites que se beneficiavam diretamente dos efeitos da modernização. Nisbet, ${ }^{2}$ quando enfoca os vários significados de progresso ao longo da história ocidental, defende que o conceito de progresso a partir da Idade Média passou a obedecer essencialmente três critérios: "o respeito pela razão, conhecimento e ciência".

Ilustra esta premissa a construção das cidades, que segundo Mumford, ${ }^{3}$ segue "um rigoroso conceito de ordem matemática", pois era preciso lutar contra as consequências de um universo citadino que crescia em meio à desordem e à destruição. Tornou-se imprescindível, além de construir as infraestruturas baseadas numa ordem, respeitar a ciência que garantiria a salubridade e a higiene, que nessa época eram raras, não só nos espaços pobres, mas também nas habitações da elite. Sendo assim, era preciso armar um contraataque aos resultados do "progresso", começando pela "arte do saneamento ou da higiene pública".

Essas novas formas de pensar que permeiam o mundo do século XIX têm suas bases no movimento iluminista da segunda metade do século XVIII, que trouxe a ideia de progresso ligada ao desenvolvimento das ciências. Segundo tal corrente filosófica, os avanços científicos se dariam cumprindo etapas sucessivas, e é dessa forma que o progresso se relacionaria à ideia de processo civilizatório. Daí se extrai um conceito de civilização ligado à tecnologia, ao crescimento do conjunto de informações científicas em geral, à evolução dos costumes, e por que não dizer, da educação, formal ou informal feminina. 
E o Brasil, acompanhando as transformações espaciais da cidade, os valores elitistas no campo sociocultural também estavam impregnados de ideias civilizadoras; buscava-se um reordenamento dos valores do bem-viver em sociedade, norteado por normas de civilidade fundamentadas nos moldes europeus. Os habitantes da cidade, que a cada dia tinham seu número aumentado, precisavam se urbanizar, precisavam aprender a viver nesse ambiente citadino, pautando-se em regras de educação, regras de urbanidade. Então, junto à racionalização dos espaços, há também uma modelação dos comportamentos em geral.

Por trás de todo o projeto social, baseado em elementos civilizatórios, havia um projeto maior, preservar a "alma feminina" dos males do mundo. E, através dela, garantir a entrada dos princípios e valores em muitos lares.

Para Léa Archanjo, ${ }^{4}$ no final do século XIX a sociedade brasileira passou por uma série de transformações sociais. A educação feminina formal, por exemplo, por meio do ensino público, passou a ser apontada como "um meio de criar condições para regenerar a sociedade". Mesmo que sua visão em relação à mulher fosse ainda muito conservadora, suas funções sociais como mãe e esposa passaram a ser mais valorizadas. Inclusive, segundo a autora, os médicos higienistas possuíam um discurso onde reconheciam a importância da família e sua influência na construção da sociedade, por isso mesmo era preciso instruí-las de forma a terem condições de desempenhar bem as funções que a sociedade esperava delas.

Seja qual fosse a corrente de pensamento, maçons, positivistas, católicos, lançam nos jornais suas ideias; cada qual com sua forma especial de valorizar os atributos das mulheres. Concordavam em frisar as características definidoras de feminilidade: "esposa, mãe e dona de casa".

Segundo Scott, ${ }^{5}$ já no final do século XIX, a abolição da escravatura, a proclamação da República, o aumento do processo imigratório junto à guinada da urbanização e industrialização, influenciaram na construção de novos modelos de organização no país. Em meio a todas essas modernizações, novos modelos de família foram recomendados. Os valores familiares divulgados eram os baseados em uma ordem burguesa, baseada no amor romântico para a escolha dos cônjuges, a intimidade passou a ser exaltada, e o lar passou a ser encarado como refúgio de um mundo árduo. Essa "nova família”, segundo a autora, precisava de uma "nova mulher", mãe dedicada à educação dos filhos, ordenamento da casa, e submissa ao marido, mas não completamente sem voz. Desobrigada dos trabalhos "produtivos" fora do lar, a mulher deveria voltar-se ao espaço da família. O homem, por sua vez, deveria ser o único, na melhor das hipóteses, ou o principal provedor das famílias.

Interessante a observação da mesma autora, que na segunda metade do século XIX a mão de obra de mulheres e crianças representava $76 \%$ da força de trabalho nas fábricas; na década de 1950 , esse número caiu para cerca de $20 \% .{ }^{5}$ Será que essas mulheres deixaram o mercado de trabalho 
para se dedicar unicamente ao lar na tentativa de colocar em prática os modelos burgueses de constituição familiar? É certo que não foi a única motivação, mas esse não é essencialmente o tema que se pretende abordar na presente pesquisa. Há que se levar em conta, aqui, o grande número de mulheres que retornaram ao lar para se dedicarem aos seus filhos e seus maridos.

Assim sendo, essas mulheres deveriam estar "preparadas" para a administração de "novo lar". Isso se dava, tanto no nível de uma educação escolar, quanto uma educação informalmente disseminada pelas tradições orais, e também a partir da imprensa feminina, aqui em especial, revistas.

Para o espaço escolar, Bastos \& Garcia ${ }^{6}$ afirmam que a formação da mulher pretendia, "preparála para o desempenho das funções a que estava destinada na sociedade, ou seja, fazer de cada aluna uma verdadeira dona de casa. Esta imagem modélica forjada pela ilustração brasileira seria dada pela economia doméstica”. No Brasil, esta apareceu nos bancos escolares com a primeira lei para a Instrução Pública Nacional, em 15 de outubro de 1827, que determinava que o ensino das "prendas domésticas" estaria relacionado aos princípios da economia doméstica. Nessa época, tal educação abrangia os trabalhos de agulha, bordado, costura e música. Mais tarde, juntaram-se a esses conhecimentos temas relacionados à cozinha, manutenção da roupa, cuidados com a limpeza da casa, higiene.

Esses ares educacionais dirigidos ao público feminino, seja por meio da escola, ou por meio de tratados ou revistas disponíveis e dispostos a construir "as rainhas do lar", forjam modelos e instigam o desejo de atendê-los. Ora, o trabalho da dona de casa não é um meramente manual, técnico, mas também é intelectual e afetivo. É um trabalho no qual se necessita de uma boa porção de criatividade, mas acima de tudo tomada de decisões. Assim, a educação feminina, formal ou informal, voltada para a "ciência do lar", objetiva uma vida melhor, com mais dignidade, visando atenuar os problemas gerados pela rotina diária da administração do espaço familiar.

É claro que esses valores não adquiriram a mesma importância na vida de todos os brasileiros e suas famílias, ressalta Scott, ${ }^{7}$ mas esse modelo de formação e funcionamento familiar estimulou o desejo de toda a população, tornando-se um parâmetro. Em busca da família ideal, esposas inexperientes, ou não, passam a recorrer à ajuda que a imprensa feminina podia oferecer. As revistas femininas apresentavam as mais valiosas dicas sobre o cuidado com a casa, o marido e os filhos. Repletas de conselhos sobre o preparo das refeições, da higiene e ordem da casa, e ainda de como agradar e deixar o marido satisfeito, assim pretendiam ajudar as mulheres a se tornarem esposas-modelo.

A felicidade conjugal parece depender cada vez mais das atividades e cuidados da mulher dentro do lar. Uma esposa que não soubesse cuidar corretamente da administração do lar, como também da imagem do marido e dos filhos, corria o sério risco de não ter um casamento feliz. 
O amor entre os cônjuges é considerado um ingrediente importante, mas não o suficiente para garantir um "casamento harmonioso". E as revistas direcionadas às mulheres trazem receitas prontas para o algo a mais que sustenta os matrimônios dentro do ideal de felicidade proposto como único e universal segundo Bassanezi: ${ }^{8}$

Em Jornal das Moças, a mulher de prendas domésticas é considerada a esposa ideal. Nesta revista, a "felicidade matrimonial" está claramente ligada à ideia de simplesmente a esposa conservar o marido que tem. Isto pode ser conseguido, entre outras coisas, pelo bom desempenho feminino nas atividades domésticas, especialmente as que podem receber mais facilmente o reconhecimento masculino, como cozinhar e deixar a casa em ordem e aconchegante.

O Jornal das Moças foi um periódico semanal produzido na cidade do Rio de Janeiro entre 1914 e 1961, e que teve circulação nacional. Saía toda quarta-feira e podia ser comprado nas bancas ou por assinatura. Foi fundado por Agostinho de Menezes, era propriedade da Editora Jornal das Moças Ltda. Possuía por volta de 70 páginas e versava sobre assuntos de interesse do público feminino de sua época, moda, novidades do mundo do cinema, culinária, crônicas e até mesmo páginas de história da arte (isso nos anos de 1950). Em todos os números, a revista trazia em sua primeira página a foto de um artista que os editores consideravam de destaque, alguém do universo hollywoodiano ou brasileiro. Seguia com notícias sobre música, cinema brasileiro e internacional, que necessariamente não apareciam logo no início de suas edições, não havia um critério definido de ordem para as matérias; versavam sempre sobre as mesmas temáticas, notícias sobre a sociedade, um pouco sobre política. Havia em todos os números uma coluna de anedotas, a "Troças e Traços", o conto da semana e notícias do rádio. Junto às edições havia uma espécie de encarte, denominado "Jornal da Mulher: Revista Semanal de Figurinos e Bordados", que trazia especialmente o universo da moda, com imagens de tendências dessa área, moldes, desenhos para "vestir" não só as mulheres, mas também suas casas, com figuras de bordados para panos de prato, por exemplo.

A metodologia utilizada para o fichamento das fontes foi agrupar em arquivos do Word as páginas digitalizadas, das edições do Jornal das Moças, no período de 1950-1959, que tivessem em seu conteúdo referência a assuntos relacionados com a alimentação, cuidados com a higiene e manutenção do lar. Tais aspectos foram encontrados nas fontes, em abordagens de assuntos variados, como por exemplo, no cuidado com os filhos, na limpeza de utensílios domésticos, dicas de regimes dietéticos, receitas, conservação de alimentos, códigos de boas maneiras, como organizar recepções em casa, forma correta de servir os alimentos, dicas de alimentos que poderiam ajudar ou prejudicar a digestão, entre várias outras abordagens em que os alimentos e a alimentação se faziam presentes. 
Claramente quando o assunto era comida, O Jornal das Moças tinha uma coluna chamada "Vamos preparar os quitutes", que aparecia quase todas as semanas, sendo raro um número em que ela não aparecia. No entanto, é interessante observar que não havia um lugar certo para ela, ou seja, como já observado acima, a revista nem sempre tinha uma ordem para a apresentação de suas colunas. Em alguns números, ela aparecia logo nas primeiras páginas, em outros números ela vem no encarte "Jornal da Mulher". Mas, mesmo que não haja um lugar certo para ela aparecer, seus temas são da mesma natureza. Nela sempre encontramos receitas de doces e salgados, bem como "coisas que as donas de casa não devem esquecer". Em março de 1950, no exemplar em que havia essa coluna, logo vinha em seguida uma propaganda do Fermento Royal, cujo título era "Hoje tem Bôlo", trazendo também a cada mês uma receita de um bolo diferente. No entanto, o tema em torno da alimentação não se restringe a essa coluna ou a propagandas da Royal ou do Óleo Saúde, mas ao longo de todo o texto há menções à comida, com conselhos, provérbios e até mesmo receitas de pratos preferidos dos artistas de Hollywood. Exemplos disso: em 08 de fevereiro de 1951, encontramos um artigo denominado "Regimes dietéticos", que apresenta a mulher como principal planejadora da alimentação doméstica e de seu próprio regime.

Cai em um grande desastre a dama que não cumpre um regime dietético perfeito, do qual todo o mundo se inteira e comenta ...às vezes com algo de ironia.

Ela se choca com o mundo em geral e com sua família em particular. Os acessos de mau humor ajudam-lhe a esquecer que os bombons não entram em sua dieta. Mas, algumas semanas depois, torna a lembrar-se, quando um vestido está apertando o corpo ou quando o marido a mira com olhos críticos. ${ }^{9}$

Em relação aos conselhos quanto à administração do lar e às responsabilidades femininas em conservar, manter, e "fazer render" os alimentos, percebemos que isso encontra muitas vezes uma referência de destaque no ano de 1950, quando na revista aparecem duas colunas, uma chamada "Pequenos truques para o lar" e outra denominada "Conselhos úteis e práticos: mágicas domésticas ao alcance de tôda dona-de-casa”.

Quanto especificamente ao objeto deste artigo, apresentar alguns conteúdos da coluna "Vamos preparar os quitutes", cabe algumas observações: em todas as suas edições ela apresenta um desenho semelhante, a chamada do título de alguma forma em destaque, mas nem sempre no mesmo lugar (às vezes está acima das notícias, às vezes no centro dos seus conteúdos, muitas vezes abaixo de uma grande imagem de iguarias). Traz também receitas diversas, e não há necessariamente uma separação entre doces e salgados. Na edição 1.864 , de 08 de março de $1951,{ }^{10}$ a coluna traz receita de "lombo ao vinagrete", "sopa de mexilhões" e "rosquinhas de gema" e em nada indica colaborar para a organização de um cardápio pronto, o que parece ser uma contribuição para que a dona de casa utilize com liberdade as receitas e elabore seu próprio cardápio a partir das receitas que lhe são apresentadas. 
Junto às receitas, sempre aparecem também dicas de economia doméstica e de conselhos na área das boas maneiras, e/ou arrumação da mesa, apresentação dos pratos, limpeza, conservação de alimentos.

Na edição 2032, de 27 de maio de 1954,, ${ }^{11} \operatorname{logo}$ abaixo de uma bela imagem de um roast-beef com grão de bico, encontramos sua receita, com ingredientes e modo de preparo, bem como deve ser sua apresentação - uma espécie de descrição por escrito da imagem que foi primeiro apresentada. Logo abaixo à esquerda o destaque vai para um pequeno "quadradinho" com o título "Bem aventurados sejam!",

Bem aventurados sejam aquêles que, compenetrados de seus deveres e perfeitos ouvintes de sua consciência, não se cansam de fiscalizar, sem tréguas, os sistemas de fabricação de material necessário à nossa alimentação. Não thes doam as mãos quando com firmes palmatoadas castigarem os que nos envenenam.

Devem êles levar seu sagrado propósito não só até às fábricas legalizadas como, principalmente, a êsses milhares de vendedores de rua que sem autorização de espécie alguma, infestam a cidade. Sejam êles as chamadas baianas, pipoqueiros, torradores de amendoim, sorveteiros, cocadeiros, pasteleiros, etc.

O coração do homem se confrange, muitas vêzes, frente a muitos que praticam tal função para sustento de sua família, mas o coração do defensor da saúde de um povo tem eu confrangir mais frente os desastres que tais guloseimas, quase sempre inescrupulosamente feitas provocam em seus consumidores, principalmente quando se trata de crianças, que constituem sua maioria.

Nessa pequena notícia pode-se vislumbrar, além da variedade da coluna, grande preocupação com a saúde num período em que avançam as visões científicas sobre higiene, preparo e comercialização dos alimentos. Também se percebe aí uma espécie de apelo ao Estado, que deveria não só fiscalizar, mas punir com propriedade os que "envenenam", mesmo que esses estejam relacionados ao espaço da tradição da comida de rua, como "as baianas" ou os "cocadeiros". Interessante como tal situação representa uma permanência na nossa sociedade frente às fiscalizações da vigilância sanitária e também as orientações da ciência quanto à ingestão de gorduras ou mesmo os perigos da contaminação.

A preocupação com a saúde também aparece, entre outras edições, no ano de $1957,{ }^{12}$ no pequeno artigo intitulado "Para vencer a anemia", onde se dá destaque ao consumo do fígado, pois de "acôrdo com a opinião de um grande cientista francês", é ele que constitui num verdadeiro elemento de combate a essa doença. Assim como outros alimentos - o espinafre e a lentilha - ele contém bastante ferro, como a carne de cavalo, ainda que se alerte na notícia que a ingestão dessa iguaria, apreciada pelos franceses, não conta com a tolerância entre os hábitos alimentares brasileiros. Em seguida, são destacasos os conselhos de "As donas de casa não devem esquecer que", alertando que "os pratos a base de fígado, como tôda fritura, devem ser confeccionados com 
esta viscera bem fresca. Se a fina envoltura que a cobre não está úmida e brilhante, sua carne ao cortá-lo, aparece opaca e sangra, é preferível não adquiri-lo e abster-se de comê-lo”. Isso posto, vê-se uma preocupação geral com o compromisso e a responsabilidade que cercam a compra, seleção, preparo, apresentação e ingestão dos "quitutes".

Em junho de $1954,{ }^{13}$ tem-se um tema para a coluna, cujo destaque não vai para o título, que aliás aparece em forma de moldura, em letras pequenas circundando todas as duas páginas onde se lê: "O mar nos proporciona deliciosos pratos". No centro, encontra-se uma foto que retrata uma bela arrumação de frutos do mar que são objeto da notícia, crustáceos, como caranguejos e lagostinhas, e moluscos, como as ostras. A reportagem traz conselhos de saúde, tanto em relação a como comprar tais produtos, quanto também modos de preparo. Dá destaque ao que chama "calorias dos crustáceos", chamando a atenção para seu alto valor nutritivo: dizendo que as ostras são ricas em lecitina e o mexilhão, em albuminas. Quanto ao preparo, conforme os produtos, destaca-se a simplicidade de algumas ao lado da sofisticação de outras. Assim tem-se para os moluscos uma receita que se diz "em salmoura",

Elimine sempre, de tôdas as maneiras, os moluscos cheio de areia. Cate e lave bastante os outros em água levemente avinagrada. Em seguida, coloque-os de môlho num recipiente. Os moluscos se abrem e abandonam suas águas. Deixe-os então, ferver durante 3 a 4 minutos. Côe a água e deixe-as aquecer com um pouco de cebola e salsa picadinhas. Sirva os moluscos num grande prato com um bom môlho numa molheira.

Seguem-se a essa receita outras três, uma denominada "poulette", outra "a moda espanhola" e uma simplesmente dita "com creme". Logo abaixo encontra-se uma receita de "Lagostinhas a americana", que talvez não seja mais sofisticada, mas melhor dizendo, mais "trabalhosa" em seu preparo.

Leve-as a cozinhar em bastante água salgada. Deixe esfriar. Retire as caudas e, numa panela, prepare um môlho com cebola e alho picados. Polvilhe com azeite doce e manteiga derretida. Molhe com vinho branco e sêco e salpique com pó de caiena, sal, salsinha picada e tomates frescos. Deixe cozinhar durante um quarto de hora; junte, depois, uma colherada de conhaque, deixe-os tostar e aqueça as caudas nas lagostinhas neste môlho. Sirva quente e coloque na beira do prato raminhos de salsa e meias rodelas de limão.

Quando se fala de boas maneiras, a coluna também traz frequentemente orientações sobre os cuidados que devemos ter quando estamos à mesa. Assim é que temos, em de março de $1959^{14}$, entre receitas de "costeletas de carneiro", "arroz dourado" e "sonhos diferentes", um destaque para "a postura à mesa”, 
A atitude à mesa é um hábito que deve ser adquirido desde criança, pois não só traduz a educação que recebe como é conveniente à saúde.

Sentado para a refeição, deve-se colocar o corpo em posição cômoda, mas correta. O corpo deve ficar em ângulo reto relativamente aos membros inferiores, bem assentados êstes sobre a cadeira. A cabeça deve conservar-se erguida e os braços mantidos o mais próximo possível do corpo, sem, todavia forçar êstes colados ao corpo.

Os talheres devem ser usados de tal forma de quem os usa não deve acotovelar o companheiro da direita ou da esquerda. Assim, a faca deve ser segura pelo cabo, não mui próximo da lâmina, e o garfo e ou a colher sôbre a mão, com a palma desta virada para cima.

O bom hábito de sentar-se à mesa conjugado com outros hábitos da natureza mental somam uma boa aquisição não só para a saúde do indivíduo mas para os eu conceito social.

Nos conselhos, dicas, truques, receitas enfim, tudo que cerca o espaço da administração do lar, dá-se especial destaque ao que envolve a comida. Pode-se revelar um patrimônio de sabores, dos gostos, assim como o legado dos requintes, os cuidados com a higiene e conservação dos alimentos, das sensações, dos laços afetivos, das lembranças registradas em forma de receitas e nele refletir sobre a responsabilidade feminina nesse conjunto. Assim, o estudo dos registros contidos nesses materiais propicia o resgate dos valores da cozinha regional e local, carregadas da história e da cultura alimentar. Pode nos trazer a possibilidade de refletir sobre as interações sociais reveladas a partir da transcrição dos saberes culinários, indicando certos padrões alimentares. A narrativa que contém uma receita nos traz situações, espaços, sentimentos; deixa vir à tona sensações de alegria, festa, prazer, comemorações, tristezas, acolhimentos - enfim, oportunidades para uma aproximação com o patrimônio imaterial. Por outro lado, os sabores também denunciam o patrimônio material, os modos de preparo, os utensílios, os ingredientes, as temperaturas, etc.

\section{Considerações finais}

O levantamento e fichamento das fontes é um fator indispensável, quando se decide analisar todas as edições de uma revista semanal. O fichamento facilita a visualização e sua posterior sistematização, e a torna mais rápida.

A cada edição, quando observamos a permanência de algumas colunas e o desaparecimento de outras, percebemos sintomas de uma sociedade que apresenta permanências e pequenas transformações. É a partir da década de 1960 que o surgimento da pílula anticoncepcional permite à mulher escolher a maternidade ou não, como também vai aos poucos proporcionando maior possibilidade para que ela decida ter uma vida profissional fora do lar. Na revista, em todos os 
anos analisados, são muitas as dicas sobre costura e moda, trazendo moldes, modelos e medidas para confecção de roupas - desta forma, a mulher que soubesse desenvolver tal atividade tinha a opção de possuir uma renda sem a necessidade de sair do espaço do lar, ou seja, trabalharia em casa, podendo ao mesmo tempo cuidar de casa e da família.

Na década de 1950, no Brasil, era forte a perspectiva de que as mulheres deveriam estar “preparadas" para a administração de um "novo lar”. Isso se dava tanto no nível de uma educação escolar, quanto uma educação informalmente disseminada pelas tradições orais, e também a partir da imprensa feminina - aqui em especial, as revistas. O mundo de grande parte do feminino estava repleto de orientações que abrangiam os trabalhos de agulha, bordado, costura e música, bem como conhecimentos de temas relacionados à cozinha, manutenção da roupa, cuidados com a limpeza da casa, higiene.

Desde o final do século XIX, no que diz respeito à educação formal, as escolas públicas adotaram o tratado Noções de vida doméstica e noções de vida prática, de F. Ferreira. Nesse período, de acordo com Bastos \& Garcia, ${ }^{15}$ o ensino na escola das chamadas "prendas domésticas" deveria contribuir para uma reforma moral, disseminando a ordem e a higiene. Assim, a educação não deveria se restringir a uma elite, mas, como interesse de todos, deveria ser destinada sobretudo às classes populares.

Esses ares educacionais dirigidos ao público feminino, seja por meio da escola, ou por meio de tratados ou revistas disponíveis e dispostos a construir "as rainhas do lar", forjam modelos e instigam o desejo de atendê-los. Ora, o trabalho da dona de casa não é um meramente manual, técnico, mas também é intelectual e afetivo; para realiza-lo, é preciso ter boa porção de criatividade, e acima de tudo, tomada de decisões. Assim, a educação feminina, formal ou informal, voltada para a "ciência do lar" objetiva uma vida melhor, com mais dignidade, visando atenuar os problemas gerados pela rotina diária da administração do espaço familiar.

Reconhecendo, portanto, que os fatores culturais, sociais e psicológicos influenciam nas escolhas alimentares - seu preparo e consumo - mas também nas outras tarefas relacionadas ao papel da dona de casa, como higiene e gestão dos gastos, é possível empreender a presente análise, na tentativa de reconhecer o alimento como elemento importante na composição da construção do modelo feminino, especialmente na década de 1950.

\section{Referências}

1. Ziegler J. Prefácio. In: Piovesan F, Conti IL, coordenação. Direito humano à alimentação adequada. Rio de Janeiro: Lumen Juris; 2007. p. ix.

2. Nisbet R. História da idéia do progresso. Brasília: Editora Universidade de Brasília; 1985. p. 16-18. 
3. Mumford LA cidade na história: suas origens, transformações e perspectivas. São Paulo: Martins Fontes; 1998.

4. Archanjo LR. Gênero e educação: relações de gênero no Colégio Estadual do Paraná (1950-1960). Curitiba: Aos Quatro Ventos; 1998. 16p.

5. Scott AS. O caleidoscópio dos arranjos familiares. In: Pinsky CB, Pedro JM, organizadores. Nova história das mulheres. São Paulo: Contexto; 2012.

6. Bastos MHC, Garcia TEM. Leituras de formação: noções de vida doméstica (1879): Félix Ferreira traduzindo Madame Hippeau para a educação das mulheres brasileiras. História da Educação 1999; 3(5):77-92.

7. Scott AS. O caleidoscópio dos arranjos familiares. In: Pinsky CB, Pedro JM, organizadores. Nova História das Mulheres. São Paulo: Contexto; 2012.

8. Bassanezi C. Virando as páginas, revendo as mulheres: revistas femininas e relações homem-mulher (1945-1964). Rio de Janeiro: Civilização Brasileira; 1996. p. 121.

9. Jornal das Moças 08 fev. 1951; (1860):59. Disponível em: http://memoria.bn.br/pdf/111031/ per111031_1951_01860.pdf

10. Jornal das Moças 08 mar. 1951; (1864):14. Disponível em: http://memoria.bn.br/pdf/111031/ per111031_1951_01864.pdf

11. Jornal das Moças 27 maio 1954; (2032):68. Disponível em: http://memoria.bn.br/pdf/111031/ per111031_1954_02032.pdf

12. Jornal das Moças 07 fev. 1957; (2173):14. Disponível em: http://memoria.bn.br/pdf/111031/ per111031_1957_02173.pdf

13. Jornal das Moças 17 jun. 1954; (2035):60-61. Disponível em: http://memoria.bn.br/pdf/111031/ per111031_1954_02035.pdf

14. Jornal das Moças 05 mar. 1959; 2281:14-15. Disponível em: http://memoria.bn.br/pdf/111031/ per111031_1959_02281.pdf

15. Bastos, M. H. C. e Garcia, T. E. M. Leituras de formação - noções de vida doméstica (1879): Félix Ferreira Traduzindo Madame Hippeau Para a Educação das Mulheres Brasileiras. In: História da Educação. Pelotas; abril de 1999.

Recebido: 15/3/2015

Revisado: $11 / 5 / 2015$

Aprovado: 29/6/2015 
